\title{
Hydroelectric Therapy in the Treatment of Lumbosacral Radiculopathy due to Degenerative Disc Disease: Pilot Study
}

\author{
Irina V. Borodulina, Nazim G. Badalov, Anastasiya A. Mukhina and Tatiana V. Marfina \\ National Medical Research Centre of Rehabilitation and Balneology, Moscow, Russian Federation, 32 Novy Arbat Street, Moscow
} 121099, Russia

\begin{abstract}
Hydrogalvanic bath is a method of combined application of warm fresh water and low frequency electric current. Procedures can be both general and local. Mechanism of therapeutic action is based on synergistic effect of two therapeutic agents. For the moment various studies show that hydrogalvanic therapy is effective in the treatment of diabetic angiopathy, rheumatoid and gouty arthritis, fibromyalgia, ankylosing spondylitis. One of the most prospective applications is treatment of lumbosacral radiculopathy due to degenerative disc disease. The present study presents preliminary results achieved in an investigation of hydrogalvanic baths as a monotherapy. Twenty-nine patients (20 women and 9 men) with lumbosacral radiculopathy lasting more than 3 months due to degenerative disc disease were included in a present prospective study. The obtained results confirm the efficacy of hydroelectric therapy in lumbosacral radiculopathy. Hydrogalvanic baths have analgesic, anti-inflammatory, and decongestant effects. They can improve microcirculation and reduce sensory impairment. Further trials are needed to determine the long-term efficacy and to compare results of hydrogalvanic bath therapy patients with control group patients receiving medication treatment only. The results will provide an opportunity to include hydrogalvanic baths in a medical rehabilitation program of patients with lumbosacral radiculopathy.
\end{abstract}

Key words: Hydrogalvanic baths, electric current, lumbosacral radiculopathy.

\section{Introduction}

Lumbosacral radiculopathy due to degenerative disc disease is one of the most common health-related complaints [1-3]. Effective management of this disorder remains a highly important clinical task because of its wide prevalence.

Treatment for patients with lumbosacral radiculopathy usually includes nonsteroid anti-inflammatory drugs, antidepressant medications, opioids, myorelaxants [4-6]. Nevertheless, studies have reported that there is no strong evidence for the effectiveness of most treatments, particularly in long-term management. Some research showed moderate efficacy of medical treatment.

Medications are considered as a first-choice therapy

Corresponding author: Irina V. Borodulina, Ph.D., Doctor, research fields: neurology, physical and rehabilitation medicine. for patients with lumbosacral radiculopathy but the problems regarding unpleasant side effects, such as gastric ulcers, nephropathy, weight gain or lack of appetite and so on, do not allow prescribing drugs for a long period [6]. Some patients have contraindications, so medical treatment for them is not possible at all.

These problems are avoided by non-medicinal treatment strategies, such as physiotherapeutic and balneological technics, special exercise programs.

Hydrogalvanic bath is considered to be an effective technic for non-medicinal treatment of patients with lumbosacral radiculopathy. The purpose of this study was to evaluate the immediate treatment effects and to investigate possible effectiveness of non-medicinal strategy.

Hydrogalvanic bath is a method of combined application of warm fresh water and electric current [7]. It can be performed as a general or local procedure. 
During general procedure the patients are completely immersed into full bathtub (Fig. 1). Feet and/or hands immersion is used during local bath, this procedure is called also "Stanger baths" (Fig. 2).

The first mention about therapeutic use of hydrogalvanic baths dates back to 1844 [8, 9]. This method was applied as early as by Ilia Cabat, Russian ophthalmologist of Saint-Petersburg military-ground hospital, for treatment of patients with eye diseases [9]. In 1873 doctor Carl Emil Schnee used local hydrogalvanic baths in the therapy of arthral disorders at the Karlsbad health resort (Fig. 3). Later, in 1883, Johann Stanger and his son Heinrich offered and substantiated potential for use in the treatment of patients with rheumatoid and gouty arthritis. They contributed to the popularization and development of the method. Since the second half of the XIX century, a term "Stanger baths" became commonly used in Europe.

In the middle of $\mathrm{XX}$ century hydroelectric procedures have been used in the treatment of different disorders, such as Parkinson's disease, neurasthenia, insomnia, and polyneuropathy [10-13]. However, there were very serious limitations for using the method associated with electrically unsafe equipment and subsequent threat to the patients' health $[14,15]$.

Afterwards, both technique and technical equipment were developed. Safer materials, such as marble, faience, and plastic, were used for bathtub production. Device for the procedures was designed using isolated electrodes and current source converter.

Several studies have shown the efficacy of hydrogalvanic baths for the treatment of patients with rheumatoid and gouty arthritis, fibromyalgia, ankylosing spondylitis and diabetic angiopathy [16-20]. Nevertheless, an amount of scientific publications and clinical researches remains very scant.

The aim of the present study was to evaluate the immediate efficacy of hydrogalvanic baths in patients with lumbosacral radiculopathy. We applied 10 sessions of general hydrogalvanic baths in a trial of patients with lumbosacral radiculopathy.

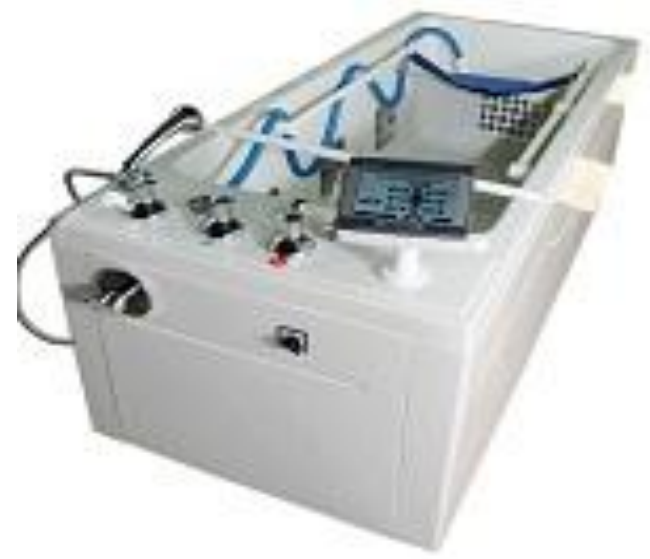

Fig. 1 A bathtub for general hydrogalvanic bath procedure, in 2014.

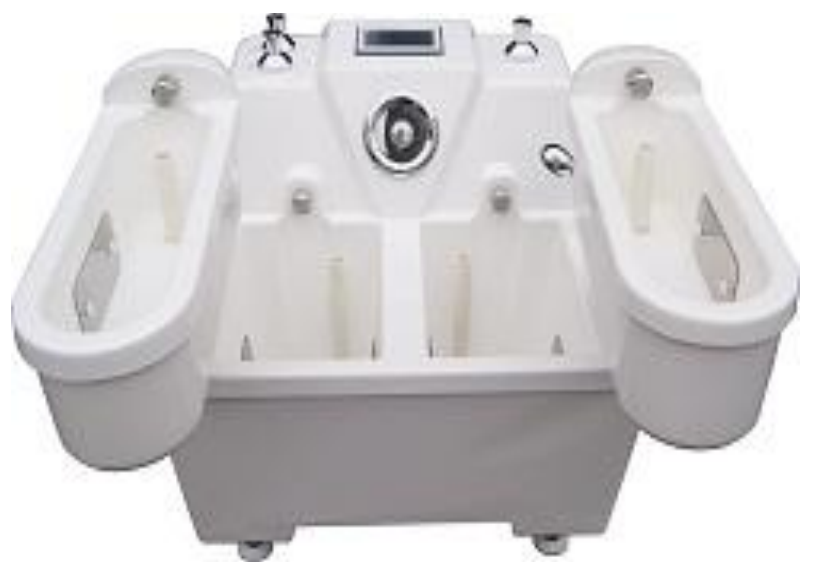

Fig. 2 A bathtub for local hydrogalvanic bath procedure, in 2014.

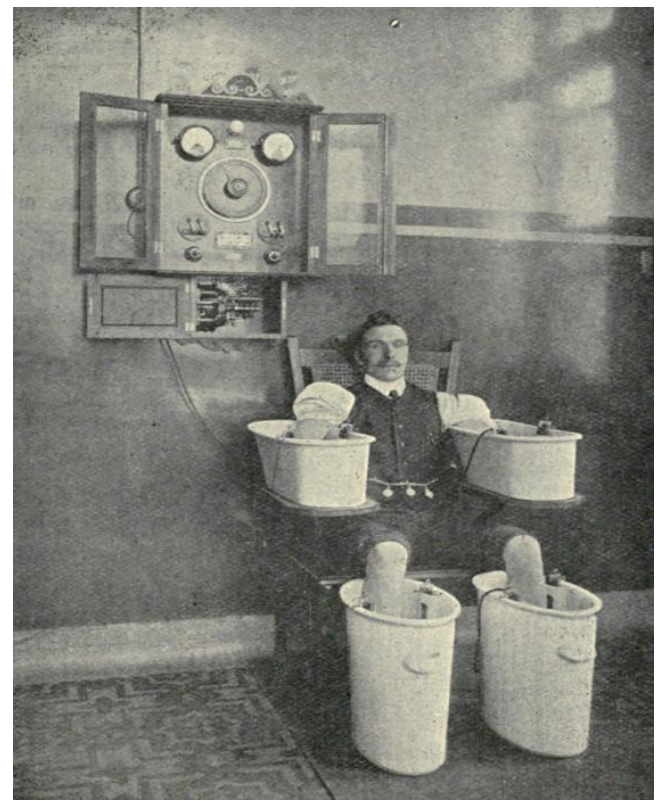

Fig. 3 Four-chamber bathtub for local hydrogalvanic bath 
procedure (Stanger bath), in 1916.

\section{Material and Methods}

\subsection{Material}

This study was conducted at the Balneology and Neurology departments, National Medical Research Centre of Rehabilitation and Balneology from November 2016 to December 2017.

For the moment this is an intermediate stage of prospective, randomized study. It is suggested that 60 patients will be included (30 patients of active group and 30 patients of control group). From November 2016, 29 patients (20 women and 9 men) with lumbosacral radiculopathy lasting more than 3 months due to degenerative disc disease were included in a prospective study of the hydrogalvanic baths. The mean (range) age of patients was 43 (25-65) years. Patients with a emerging infection diseases, a pacemaker or other metal implants, as well as concurrent pregnancy, malignancy or physiotherapy during the study, were excluded. The medical history and previous treatments were documented (drugs, physiotherapy, or a combination of therapies). Twenty nine patients were recruited in the present study, 1 case was excluded (a female patient received single hydroelectric procedure, after that she got sick with infectious respiratory disease). Hydrogalvanic baths were used as a monotherapy without any additional drug administration but if patients received some medications administered before hydrogalvanic baths procedures, they continued pharmacological therapy.

\subsection{Clinical Assessment}

Each subject underwent a clinical neurological examination, and completed a VAS (visual analogue scale), DN4 (Neuropathic Pain Diagnostic Questionnaire), PainDetect, ODI (Oswestry Disability Index), BDI (Beck Depression Inventory) at baseline, at the end of the treatment (the last day of treatment) and 3 months after the end of treatment.

The DN4 and PainDetect include questions to define presence and intensity of neuropathic component in the pain syndrome. ODI was used to quantify disability for low back pain and back problems from the patient's point of view. The self-completed questionnaires contains ten topics concerning intensity of pain, lifting, ability to care for oneself, ability to walk, ability to sit, sexual function, ability to stand, social life, sleep quality, and ability to travel. BDI was used as a diagnostic test for measuring the severity of comorbid depression. It contains 21 questions relating to symptoms of depression such as hopelessness and irritability, cognitions such as guilt or feelings of being punished, as well as physical symptoms such as fatigue, weight loss, and lack of interest in sex.

These scales are the practical, reliable and valid measure of physical and mental health that can be completed in ten to fifteen minutes.

\subsection{Procedure}

During treatment, the patients have been immersed into full bath of fresh medium-temperature water (37-38 Celcius degrees). We applied head out full body immersion. Patients removed all metal items and jewelry before procedure.

A procedure was provided by current flow originating from 3 pairs of electrodes. Electrodes are placed onto inner bath wall transversally. The generator created diadynamic currents with a frequency of $100 \mathrm{~Hz}$. The current intensity was gradually increased up to the limit of tolerability as indicated by the patient (average 200-350 mA). Treatment was repeated for 10 sessions, 5 sessions per week with 2 days off. This regimen was a practical schedule for patients.

\subsection{Outcome}

Primary outcome: The primary outcome was the pain syndrome decreasing and improvement of sensory impairments.

\subsection{Ethical Approval}


The study was approved by the Institutional Ethical

Table 1 Questionnaires change before treatment and after treatment assessment.

\begin{tabular}{llll}
\hline Variables & Before treatment & End of treatment & $p$-value \\
\hline Visual analogue scale (median $(25 \%-75 \%))$ & $5(3.75-5)$ & $3(1-5)$ & $<0.01$ \\
DN4 questionnaire (median $(25 \%-75 \%))$ & $3,5(2.75-5)$ & $2(1-3)$ & $<0.01$ \\
PainDetect (median $(25 \%-75 \%))$ & $9(7-12.25)$ & $9(4.75-11)$ & $<0.05$ \\
Oswestry Disability Index (median $(25 \%-75 \%))$ & $28(22-36.05)$ & $17(12.25-23.15)$ & $<0.01$ \\
Beck Depression Inventory (median $(25 \%-75 \%))$ & $13(7.75-16)$ & $8,5(2.75-10.25)$ & $<0.01$ \\
\hline
\end{tabular}

Committee of National Medical Research Centre of Rehabilitation and Balneology. Prior to the investigation, patients gave their informed consent according to the declaration of Helsinki.

\subsection{Statistical Analysis}

Variables were checked for abnormal distribution using nonparametric tests. The Wilcoxon's matched pairs test was used to examine differences between baseline and the end of treatment (14th day) with $p<$ 0.05 considered statistically significant in all analyses. Median (25\%-75\%) was calculated for each of the primary and secondary variables.

\section{Results}

All patients were able to attend all sessions. There were no side effects recorded from hydrogalvanic baths in the present study. We evaluated the immediate effect of hydrogalvanic baths (the last day of treatment) because we have a lack of data to show long-term efficacy.

The obtained preliminary results indicate that hydrogalvanic bath treatment had a significant effect on the decreasing of pain intensity (nociceptic and neuropathic components both), symptoms of comorbid depression, quality of life improvement (Table 1).

The therapeutic effect was observed after the 3rd-4th procedure.

Twenty-four patients noticed sensory improvement that was observed during neurological examination after treatment.

\section{Discussion}

The results of this study confirm the efficacy of hydroelectric therapy in lumbosacral radiculopathy. It must be pointed out that the effectiveness of hydrogalvanic bath therapy has been well-documented and we can infer that the effects observed in this treatment are not due to placebo [17-20]. The present study presents preliminary results achieved in an investigation of non-medicinal method as a monotherapy.

Hydrogalvanic baths relieved leg pain, reduced symptoms of depression and improved the patients' quality of life. These effects were positively perceived both by the patients and doctors. Improvement of radiculopathy-related sensory deficit was a significant therapeutic benefit.

However, the mechanism of therapeutic action is unclear. It is considered to be based on synergistic effect of two agents: warm fresh water and electric current. To our knowledge, warm water has two main effects: thermal and mechanical. Both of these factors increase the potential of adaptive reactions and have a training effect on cardiovascular, thermoregulatory and respiratory systems $[7,21]$. Besides, some authors have noticed sedative action of indifferent temperature water [7, 22].

Another agent of therapeutic action is electric current. Modern technical equipment allows choosing any type of current. We applied diadynamic current with a frequency of $100 \mathrm{~Hz}$ because of its anti-inflammatory, pain relief and microcirculation improvement effects that have been shown by different authors [23-27]. To our opinion, the key advantage of general hydrogalvanic bath technic is a larger therapeutic effect due to increased area of exposure.

Sensory improvement is likely mediated by change 
of microcirculation and stimulation of afferent and autonomic nerves.

Despite the diverse types of treatment lumbosacral radiculopathy, its safe and effective conservative management is a challenge for clinicians. All patients of our study were treated with medication for a long period of time, most of them reported about severe side effects. Therefore, we found a great compliance of patients to drug-free treatment.

\section{Conclusion and Recommendations}

From these results, hydrogalvanic baths seemed effective on lumbosacral radiculopathy due to degenerative disc disease. As evidenced by our results, hydrogalvanic bath therapy has its role in the conservative management of such patients.

Further trials are needed to determine the long-term efficacy and to compare results of hydrogalvanic bath therapy patients with control group patients receiving medication treatment only.

\section{Funding Statement}

The authors received no financial support for the research, authorship, and publication of this article.

\section{Conflict of interest}

We declare no conflict of interest.

\section{References}

[1] Frymoyer, J. W. 1992. "Lumbar Disk Disease: Epidemiology." Instr Course Lect. 41: 217-23.

[2] Weber, H. 1983. "Lumbar Disc Herniation: A Controlled, Prospective Study with Ten Years of Observation." Spine 8: 131-40.

[3] Suri, P., Hunter, D. J., Jouve, C., Hartigan, C., Limke, J., Pena, E., et al. 2011. "Nonsurgical Treatment of Lumbar Disk Herniation: Are Outcomes Different in Older Adults?" J Am Geriatr Soc. 59: 423-9.

[4] Skouen, J. S., Brisby, H., Otani, K., et al. 1999. "Protein Markers in Cerebrospinal Fluid in Experimental Nerve Root Injury: A Study of Slow-Onset Chronic Compression Effects or the Biochemical Effects of Nucleus Pulposus on Sacral Nerve Roots." Spine 24 (21): 2195-200.

[5] Podchufarova, E. V. 2010. "Discogenic Lumbosacral Radiculopathy." Neurology, Neuropsychiatry,
Psychosomatics 3: 22-9.

[6] Borodulina, I. V., Suponeva, N. A., and Badalov, N. G. 2016. "Nonspecific Back Pain: Clinical Pathogenic Features and Therapeutic Modalities." Russkii Meditsinskii Zhurnal 25: 1699-704.

[7] Olefirenko, V. T. 1986. Vodoteplolechenie. Moscow: Meditsina.

[8] Reituzov, V. A., Kulikov, A. N., and Volozhev, A. A. 2017. "Vklad II Kabata v razvitie oftal'mologii." Novosti Glaukomy 1: 77-8.

[9] Kabat, I. I. 1844. Opyty primeneniya gal'vano-magnitnogo toka posredstvom vody $k$ lecheniyu boleznei, proizvedennye $v$ glaznom otdelenii 2-go Sankt-Peterburgskogo voenno-sukhoputnogo gospitalya. Saint-Petersburg.

[10] Syroechkovskaya, M. N. "Gidroelektricheskaya Vanna." Problems of Balneology, Physiotherapy, and Exercise Therapy 38 (5): 447-50.

[11] Krischek, J. 1953. "Parkinson's Disease and Parkinsonism as Indications for the Stanger Bath." Arztl Wochensch 8 (27): 651-2.

[12] Morton, E. R., and Cumberbatch, E. P. 1916. "Essentials of Medical Electricity." Archives of Radiology and Electrotherapy 21 (1): 36.

[13] Whitby, C. J. 1990. "Notes on Some Thermal, Hydro-Thermal, Electric and Hydro-Electric Procedures, and the Indications for Their Use." Bristol Med Chir J. 18 (67): 1-16.

[14] Behrend, H. J. 1937. "Modern Hydrotherapy." Arch Phys Ther X-ray Radium 18: 146.

[15] Kovacs, R. 1945. Electrotherapy and Light Therapy. Philadelphia: Lea \& Febiger.

[16] Günther, V., Mur, E., Kinigadner, U., and Miller, C. 1994. "Fibromyalgia-The Effect of Relaxation and Hydrogalvanic Bath Therapy on the Subjective Pain Experience." Clin Rheumatol. 13 (4): 573-8.

[17] Eksioglu, E., Yazar, D., Bal, A., et al. 2007. "Effects of Stanger Bath Therapy on Fibromyalgia." Clin Rheumatol. 26 (5): 691-4.

[18] Gurcay, E., Yuzer, S., Eksioglu, E., et al. 2008. "Stanger Bath Therapy for Ankylosing Spondylitis: Illusion or Reality?" Clin Rheumatol. 27 (7): 913-7.

[19] Mukhina, A. A., Badalov, N. G., and Artikulova, I. N. 2012. "Obshchie gidrogal'vanicheskie vanny v lechenii bol'nykh diabeticheskoy angiopatiey i polineyropatiey." Fizioterapevt. 8: 65-9.

[20] Badalov, N. G., Turova, E. A., Mukhina, A. A., et al. 2013. "Primenenie obshchikh gidrogal'vanicheskikh vann v meditsinskoy reabilitatsii bol'nykh diabeticheskoy angiopatiey." Vestnik vosstanovitel'noy meditsiny. 3: 20-5

[21] Lehr, G. 1885. The hydroelectric baths. Wiesbaden.

[22] Thompson, D. L. 1949. "Hydrogalvanic Definition." $J$ 


\section{Hydroelectric Therapy in the Treatment of Lumbosacral Radiculopathy}

due to Degenerative Disc Disease: Pilot Study

Nature Medicine Association 2: 26.

[23] Korotnev, N. I. 1927. Osnovy elektroterapii $i$ elektrodiagnostiki. Moscow: Meditsina.

[24] Erb, W. 1883. Handbook of Electro-Therapeutics. New York: William Wood \& Co.

[25] Wedekind, W. H. "Untersuchungen ueber elektrische
Vollstrom und Teilstrombaeder." Ztschrfd ges phys Ther. 43 (4): 262-4.

[26] Cumberbatch, E. P. 1921. Essentials of Medical Electricity. London: Henry Kimpton.

[27] Yasnogorodskiy, V. G. 1987. Elektroterapiya. Moscow: Meditsina. 